\title{
Article \\ HPW/PAM Catalyst for Oxidative Desulfurization-Synthesis, Characterization and Mechanism Study
}

\author{
Ziyang Zheng ${ }^{1, \dagger}$, Qian $\mathrm{Wu}^{2, \dagger}$ and Shengyang Zhong ${ }^{1, *(1)}$ \\ 1 Department of Real Estate Studies, Konkuk University, Seoul 05029, Korea; zhengzi@konkuk.ac.kr \\ 2 Business School, Jiangsu Normal University, Xuzhou 221116, China; wuqian@jsnu.edu.cn \\ * Correspondence: zhongsy@konkuk.ac.kr \\ + These authors contributed equally to this work.
}

check for updates

Citation: Zheng, Z.; Wu, Q.; Zhong, S. $\mathrm{HPW} / \mathrm{PAM}$ Catalyst for Oxidative

Desulfurization-Synthesis,

Characterization and Mechanism

Study. Processes 2022, 10, 402.

https://doi.org/10.3390/pr10020402

Academic Editor: Chiara Bisio

Received: 4 January 2022

Accepted: 16 February 2022

Published: 18 February 2022

Publisher's Note: MDPI stays neutral with regard to jurisdictional claims in published maps and institutional affiliations.

Copyright: (C) 2022 by the authors. Licensee MDPI, Basel, Switzerland. This article is an open access article distributed under the terms and conditions of the Creative Commons Attribution (CC BY) license (https:// creativecommons.org/licenses/by/ $4.0 /)$.

\begin{abstract}
In this work, polyacrylamide (PAM) was first used in the loading of heteropoly acids, and then the HPM/PAM-n catalyst was synthesized by simple reaction. The FTIR and SEM measurements showed that the HPM/PAM-n ( $\mathrm{n}=10,000,20,000,30,000)$ was successfully synthesized. In addition, the HPM/PAM-n effect on desulfurization was measured, which showed the optimal desulfurization efficiency. The optimal process condition for HPM/PAM-10000 desulfurization was optimized by a single-factor experiment. The optimal condition was as follows: The temperature was $60^{\circ} \mathrm{C}$, the amount of the catalyst was $0.2 \mathrm{~g}$, the oxygen to sulfur ratio was 16 , and the reaction time is $100 \mathrm{~min}$. The catalyst was suitable for recycled use, and the desulfurization efficiency was high after 10 times. In the end, the oxidative desulfurization mechanism was put forward.
\end{abstract}

Keywords: PAM; desulfurization; heteropoly acid; recycle use

\section{Introduction}

In recent years, fossil fuels have played an important role in global industrial production. However, the combustion of sulfur-containing compounds in fuels can cause the air deterioration, health hazards to organisms, etc. Traditional hydrodesulfurization $[1,2]$ (HDS) is the most effective method of removing mercaptans and thioethers. However, the HDS process is limited to the extreme process conditions. In order to solve these problems, non-HDS methods were put forward, such as oxidative desulfurization (ODS) [3,4], extractive desulfurization (EDS) [5-7] and adsorption desulfurization (ADS) [8-10].

$\mathrm{Xu}$ et al. [11] studied the $\mathrm{PdO} / \mathrm{SiO}_{2} @ g r a p h e n e$ effect on the adsorption desulfurization, and the graphene oxide effect was observed. The results showed $\mathrm{PdO} / \mathrm{SiO}_{2} @ \mathrm{GO}$ had higher adsorption performance for thiophene than $\mathrm{PdO} / \mathrm{SiO}_{2}$. Carla et al. [12] studied the effect of bio-based chitosan and cellulose ionic liquid gels on fuel desulfurization, and the results showed that the bio-based polymer had a high desulfurization removal efficiency for thiophene and dibenzothiophene. Wang et al. [13] studied the polyoxometalate-based catalyst $[\mathrm{MIMPs}]_{3} \mathrm{PMo}_{6} \mathrm{~W}_{6} \mathrm{O}_{40}$ synthesis and characterization, and the results showed that all dibenzothiophene in the model oil could be removed at a low $\mathrm{O} / \mathrm{S}$ ratio. Su et al. [14] studied the $\mathrm{TiO}_{2}$ quantum dots catalysts effect on enhanced oxidative desulfurization, and the results showed that the catalysts could achieve $100 \%$ desulfurization with $50 \mathrm{mg}$. Wang et al. [15] synthesized the W2C@C catalysts from metallophthalocyanine/phosphotungstic acid composites, and the catalyst was used to oxidatively desulfurize. Dibenzothiophene (DBT) was $100 \%$ removed by W2C@C within $40 \mathrm{~min}$ at $50^{\circ} \mathrm{C}$. Zhong [16] et al. studied the Zr-Based phosphotungstic acid catalyst and explored the oxidative desulfurization efficiency.

Compared to other methods, the ODS is more advantageous. In recent years, many researchers have focused on high desulfurization efficiency catalysts for the ODS process $[9,17,18]$. The carriers of catalysts were synthesized and utilized, for instance, $\mathrm{SiO}_{2}$ [18], graphene [9], polyionic liquids [19,20], $\mathrm{MnO}_{2}$ [20] and molecular sponges [21]. Among these carriers of catalysts, polyacrylamide was an ideal polymer carrier. The synthesis of polyacrylamide 
method is simple, and quantities of amine functional groups help disperse heteropolyacids [22,23]. In recent years, many experiments on polyamide desulfurization have been reported. Yen et al. studied some characteristics of flue gas desulfurization (FGD) in polyamide membranes [24]. Yu et al. used polyamide compounds to prepare a highperformance membrane and tested the desulfurization effect [25]. The detailed catalysts used in the ODS process are shown in Table 1.

Table 1. Different catalysts used in the ODS process.

\begin{tabular}{|c|c|c|c|c|c|c|}
\hline Catalyst & $\begin{array}{l}\text { Sulfur Content } \\
\text { (ppm) }\end{array}$ & $\begin{array}{c}\text { Temperature } \\
\left({ }^{\circ} \mathrm{C}\right)\end{array}$ & $\begin{array}{l}\text { Time } \\
\text { (min) }\end{array}$ & $\mathrm{O} / \mathrm{S}$ & $\begin{array}{c}\text { Sulfur Removal } \\
(\%)\end{array}$ & Reference \\
\hline $\mathrm{Nb}_{2} \mathrm{O}_{5} / \mathrm{Al}_{2} \mathrm{O}_{3}$ & 55 & 110 & 180 & 1.5 & 43.42 & [26] \\
\hline $\mathrm{Al}_{2} \mathrm{O}_{3}-\mathrm{P}_{2} \mathrm{~W}_{15}-\mathrm{C}_{18}$ & 1000 & 60 & 9 & 3 & 100 & [27] \\
\hline Ag-ZSM5/SBA-15 & 1000 & 70 & 120 & - & 44 & [28] \\
\hline TMU-10 & 500 & 60 & 360 & 3 & 74.7 & [29] \\
\hline $\mathrm{NH}_{2}-\mathrm{TMU}-53$ & 500 & 60 & 120 & 3 & 79.4 & [30] \\
\hline DES & 100 & 25 & - & 2 & 79.01 & [31] \\
\hline PAF-30-W & 500 & 60 & 120 & 6 & 60 & {$[32]$} \\
\hline 0.5-HPMo@UiO-66-D & 800 & 60 & 60 & 8 & 100 & [33] \\
\hline $\mathrm{SiO}_{2} @ \mathrm{~V}-\mathrm{PIL}-70$ & 500 & 50 & 90 & 5 & 99 & {$[34]$} \\
\hline Cu@Al-PMO-TU & - & 120 & 25 & - & 100 & [35] \\
\hline
\end{tabular}

The aim of this research was (i) to synthesize the HPW / PAM-n desulfurization carriers, (ii) to characterize the corresponding desulfurization carriers and (iii) to explore the oxidative desulfurization effect, mechanism and recycle use.

\section{Experimental}

\subsection{Materials}

Dibenzothiophene was analytical grade and from West Asia Chemical Technology Co., Ltd., (Linyi, China), Phosphotungstic acid, polyacrylamide and 4,6-dibenzothiophene, 3-methyl1-octyl imidazolium tetrafluoroborate were analytical grade and from Aladdin. N-octane, hydrogen peroxide (30\%) and benzenethiophene were analytical grade and from Shanghai Mike Lin Biochemical Technology, Shanghai, China.

\subsection{Synthesis of HPW/PAM- $n$}

First, the PAM and phosphotungstic acid were weighed, and the molar ratio was n. Then, PAM and phosphotungstic acid were dispersed in deionized water. The phosphotungstic acid solution was added dropwise to the PAM solution, and then stirred for $1 \mathrm{~h}[36,37]$. After $1 \mathrm{~h}$, the product was filtered, washed and dried to produce HPW /PAM-n.

\subsection{Characterization}

\subsubsection{FTIR Measurement}

The HPW/PAM-n FT-IR spectra were recorded at room temperature on a Nexus 470 FT-IR spectrometer. The measured samples were analyzed by the potassium bromide tablet pressing method, and the scanning wavenumber range was $3800-400 \mathrm{~cm}^{-1}[38,39]$.

\subsubsection{SEM Measurement}

The morphologies of the HPW/PAM-n were observed by scanning electron microscopy (JSM-7100F (JEOL, Ltd.)) [40].

\subsection{Oxidative Desulfurization Experiment}

The thiophene compound and n-octane were mixed to prepare a certain sulfur content simulated oil. In total, $10 \mathrm{~mL}$ of the simulated oil and $0.2 \mathrm{~g}$ of the catalyst were placed in the flask. After the set temperature was stabilized, hydrogen peroxide was added to cause the reaction. After $\mathrm{t}$ min, the oil layer was analyzed by a fluorescence analyzer. Sulfur removal 
(desulfurization efficiency) was calculated by Equation (1), where $C_{0}$ is the initial sulfur content, and $C_{t}$ is the residual sulfur content after the reaction was continued $t$ min.

$$
\text { Sulfur removal }(\%)=\frac{C_{0}-C_{t}}{C_{0}}
$$

The reaction flask was charged with $1 \mathrm{~mL}$ of 3-methyl-1-octyl imidazolium tetrafluoroborate to extract sulfur oxides. The oil layer was in the upper layer, and the ionic liquid was extracted in the lower layer.

\section{Results}

\subsection{Characterizations of Catalysts}

\subsubsection{FTIR}

Figure 1 presents the FTIR spectra of the HPW / PAM-10000, HPW / PAM-15000 and HPW / PAM-20000 catalysts. All catalysts showed two different peaks at $1417 \mathrm{~cm}^{-1}$ and $1647 \mathrm{~cm}^{-1}$. Whereas $1647 \mathrm{~cm}^{-1}$ was the bending vibration peak of $\mathrm{N}-\mathrm{H}, 1417 \mathrm{~cm}^{-1}$ was the absorption peak of the methylene group (amide portion of the polymer). The $1100 \mathrm{~cm}^{-1}$ peak was the stretching vibration of $\mathrm{C}-\mathrm{H}$. There was a broad peak $\left(3200 \mathrm{~cm}^{-1}\right)$, which was a hydrated molecular $\mathrm{O}-\mathrm{H}$ bond of heteropoly acid. The $-\mathrm{NH}_{2}$ vibration peak was lost because the hydrated molecule of the heteropoly acid vibration peak obscured the amine group vibration peak. Figure 1 indicates the polymer catalyst was successfully synthesized.

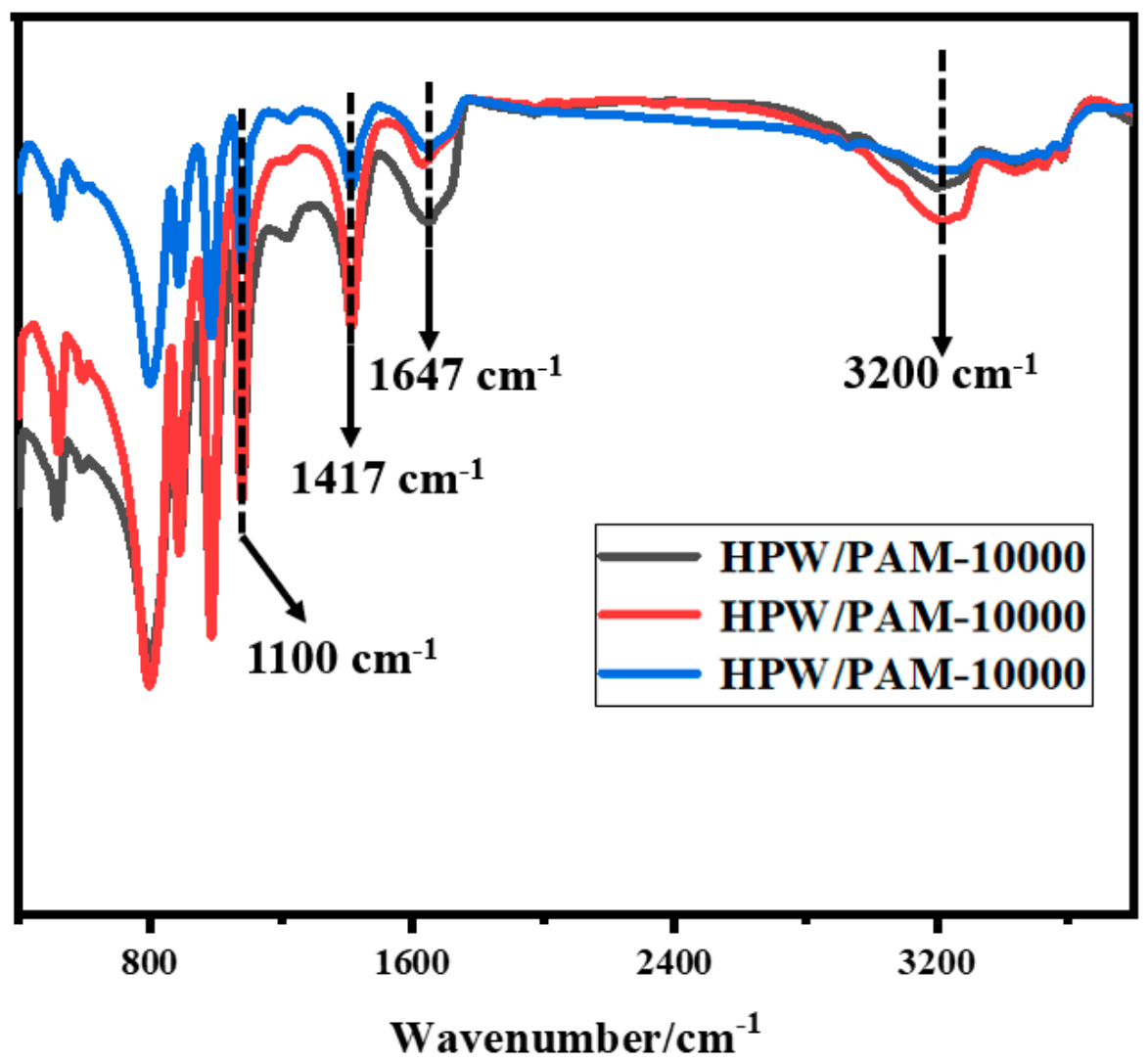

Figure 1. FT-IR spectra of HPW/PAM-10000, HPW/PAM-15000 and HPW/PAM-20000.

\subsubsection{SEM}

As shown in Figure 2, the catalyst morphology was different under different loading amounts. Figure 2A indicates that the polymer showed a curtain shape with specific properties when the loading amount was low. The heteropoly acid was uniformly distributed on the polymer, and the morphology of the heteropoly acid was complete. When the load increased ( $n$ value increased), the heteropoly acid amount increased, and the distributed 
curtain state was much more uniform. The catalyst stability decreased with high load amount. Figure 2C indicates that the HPW /PAM-20000 catalyst was in an amorphous state, and the effective contact area of the catalyst was greatly reduced.
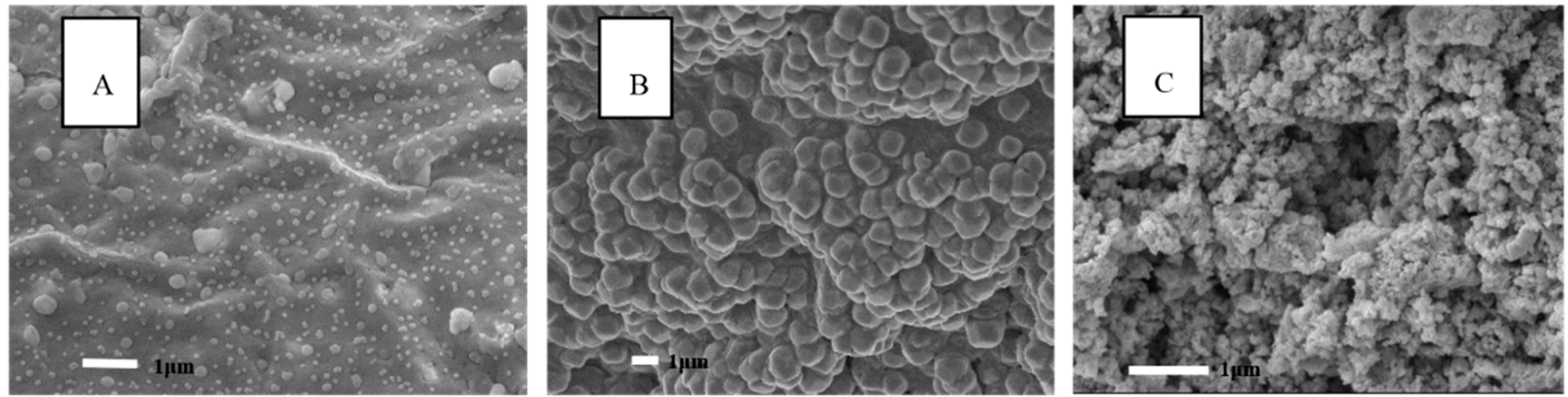

Figure 2. SEM images of (A) HPW/PAM-10000, (B) HPW/PAM-15000 and (C) HPW /PAM-20000.

\subsection{Desulfurization Performance of Catalysts}

As shown in Figure 3, the desulfurization efficiency of different catalysts (HPW/PAMn) was different. The desulfurization efficiency decreased with the increase of the load ( $n$ value) because the higher $\mathrm{n}$ value led to the fusion of heterozygosis, and the exposed contact sites decreased. Therefore, HPW /PAM-10000 was chosen as the catalyst for the next experiment. The desulfurization efficiency increased with the increase of reaction time. The desulfurization efficiency reached the highest value when the reaction time was $100 \mathrm{~min}$. The DBT removal rate by HPW/PAM-10000 reached $76.9 \%$ after $100 \mathrm{~min}$.

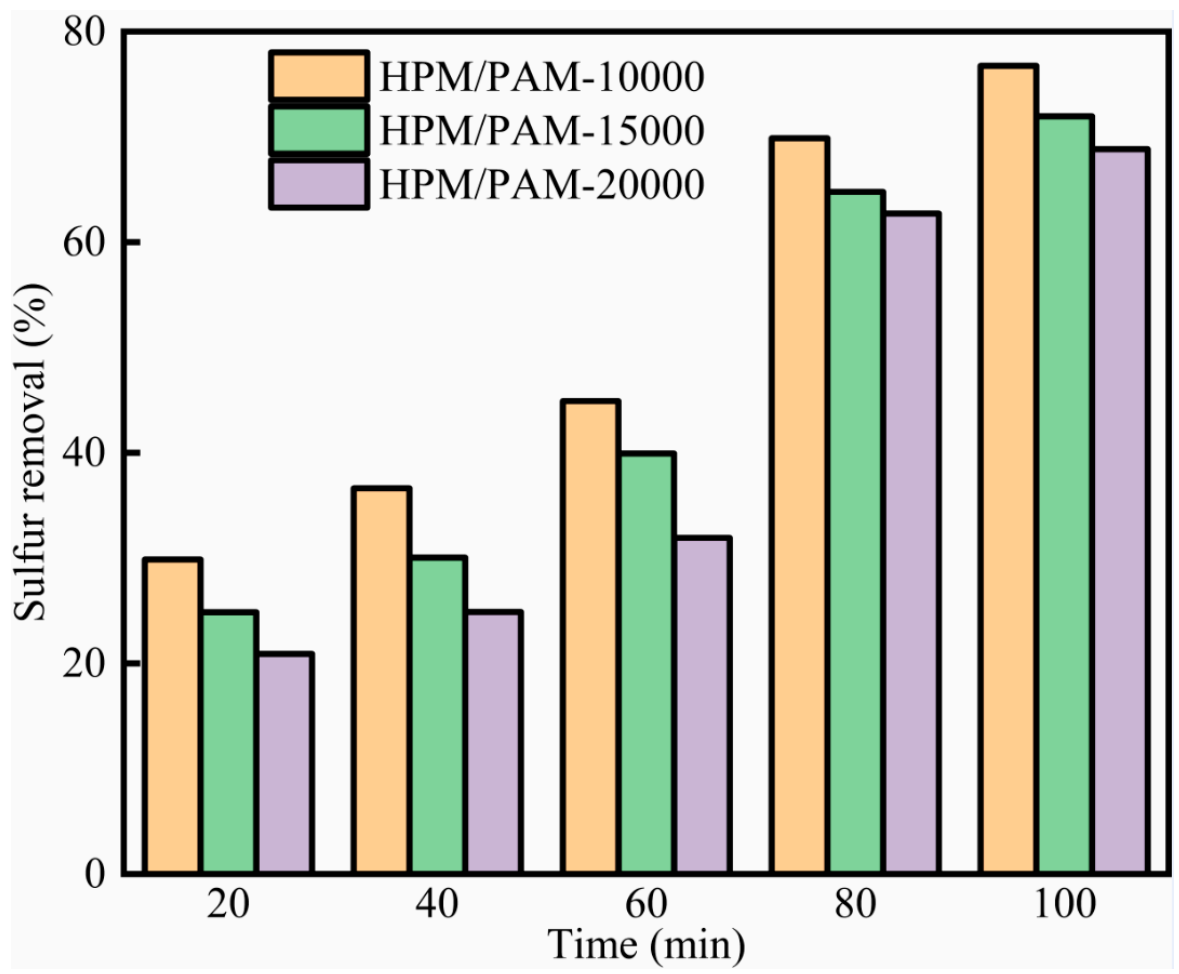

Figure 3. Desulfurization efficiency for HPM/PAM-n catalysts at different reaction times (initial sulfur content $=500 \mathrm{ppm} ; \mathrm{T}=60^{\circ} \mathrm{C} ; \mathrm{V}($ oil $)=10 \mathrm{~mL} ; \mathrm{m}$ (catalyst) $\left.=0.2 \mathrm{~g} ; \mathrm{n}(\mathrm{O}) / \mathrm{n}(\mathrm{S})=16\right)$.

The different oxygen to sulfur ratio, initial sulfur content, temperature and sulfur compounds effect by HPW/PAM-10000 on desulfurization efficiency is shown in Figure 4. As shown in Figure 4a, the HPW/PAM-10000 desulfurization efficiency increased with the 
increase of $\mathrm{O} / \mathrm{S}$. When the $\mathrm{O} / \mathrm{S}$ was 16 , the desulfurization efficiency remained stable, which was because liquid sealing hindered the reaction under high water content. As shown in Figure 4b, the HPW / PAM-10000 desulfurization efficiency increased when the reaction time increased. When the initial sulfur content increased, the desulfurization efficiency increased because the contact area between oxygen molecules and sulfur compounds increased at the high sulfur content. When the initial sulfur content was higher than $250 \mathrm{ppm}$, the desulfurization increased slightly. As shown in Figure $4 c$, when the temperature increased from $30{ }^{\circ} \mathrm{C}$ to $60{ }^{\circ} \mathrm{C}$, the HPW/PAM-10000 desulfurization efficiency increased from $37.5 \%$ to $76.9 \%$, which can be attributed to the increase of the decomposition rate of hydrogen peroxide with higher temperature, enabling oxygen molecules to effectively react with sulfur compounds. As shown in Figure $4 d$, the desulfurization efficiency was DBT > BT > 4, 6-DMDBT. Different sulfur compounds have different electron clouds densities and spatial resistances, and the reaction rate between sulfur and oxygen molecules was different.
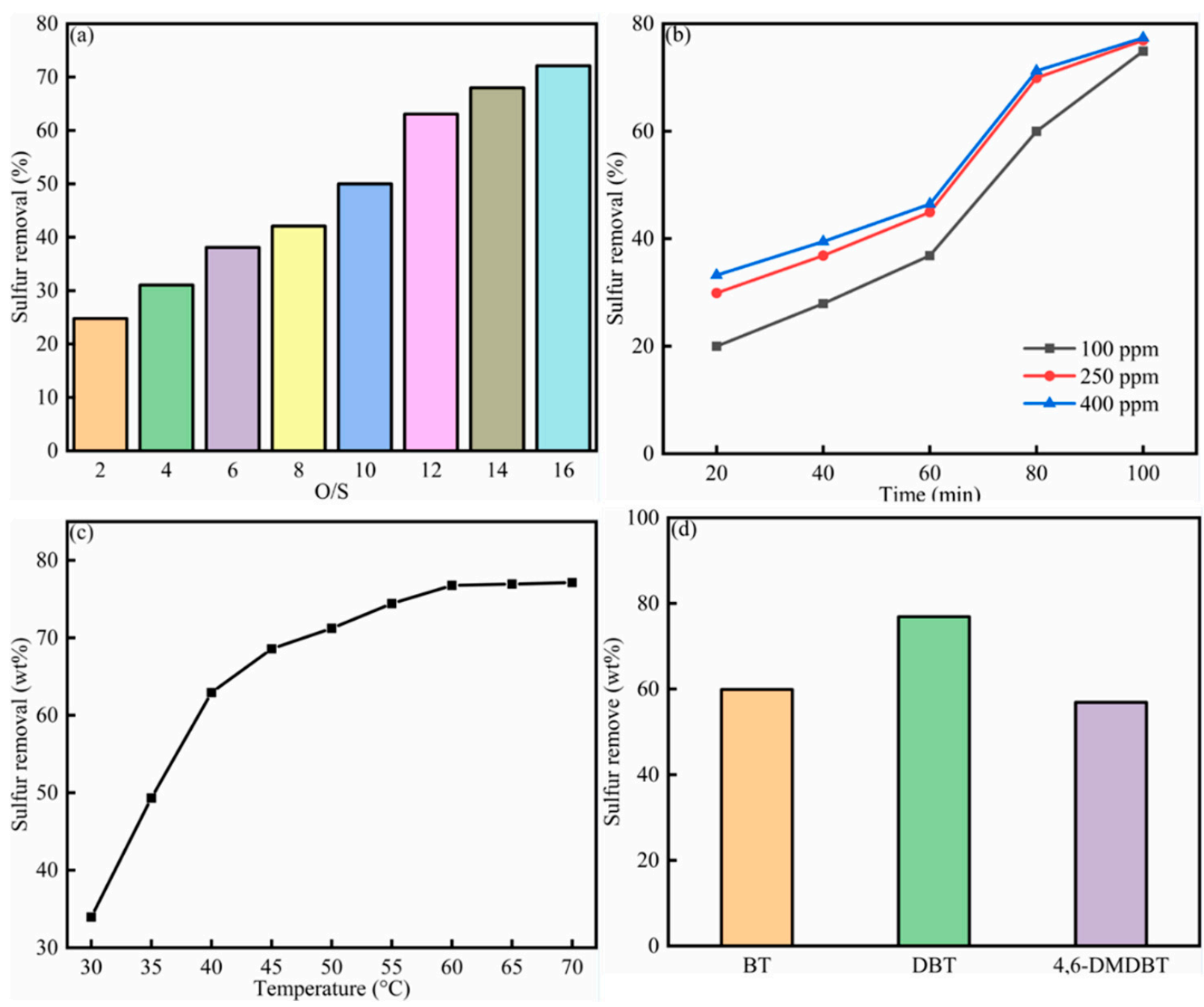

Figure 4. HPW / PAM-10000 desulfurization efficiency changed with (a) the oxygen to sulfur ratio, (b) initial sulfur content, (c) temperature and (d) sulfur compounds species.

\section{Catalyst Recycling}

As shown in Figure 5, the HPW / PAM-10000 effect on desulfurization was explored. The desulfurization efficiency remained high after recycling 10 times. Compared to the first time, the sulfur removal of the tenth time decreased slightly. The results showed that the 
HPW /PAM-1000 was economically feasible. The slight desulfurization efficiency decrease was due to the amount of active site loss.

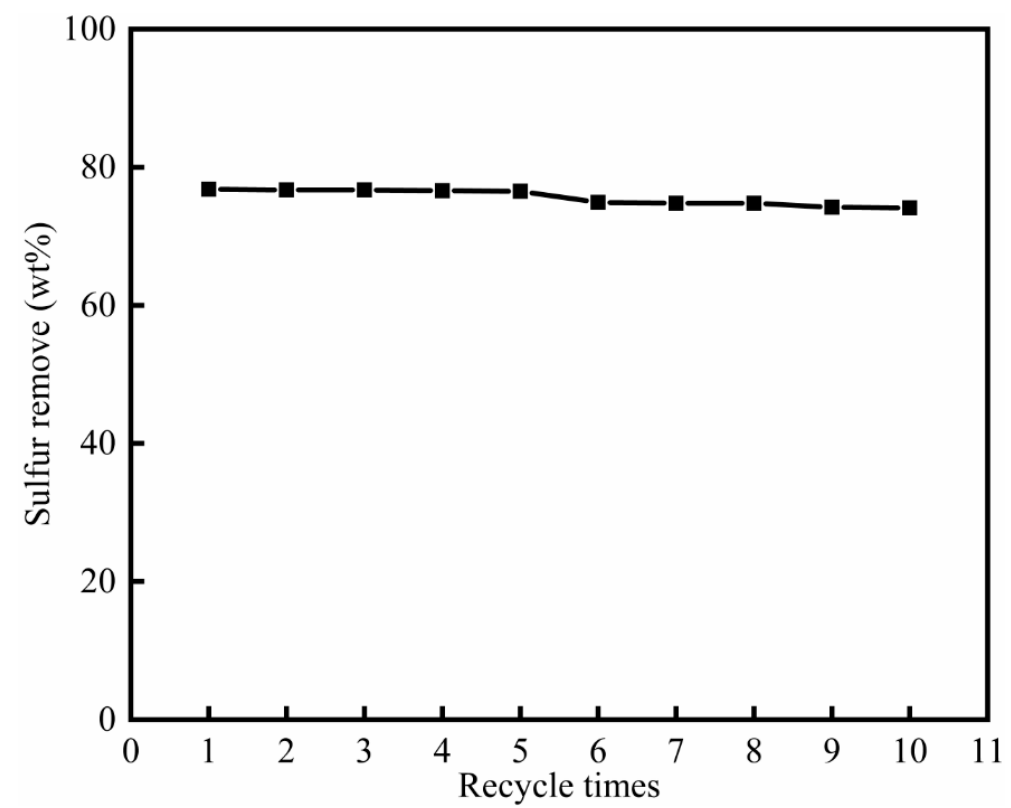

Figure 5. Recycling of the catalyst.

\section{Reaction Mechanism}

As shown in Figure 6, phosphotungstic acid was a good catalyst for oxidative desulfurization. Its active center can decompose hydrogen peroxide as water and oxygen. Then, its active center $\mathrm{W}$ can act to transport oxygen molecules, transporting oxygen molecules to specific locations for reaction. Of course, the $W$ valence state of the event center will also change $[36,41]$. When an oxygen molecule was successfully transported and reacted with the sulfur compound, its valence returned to its original valence state, and the process was repeated until all oxygen molecules were transported. At this time, the sulfur compound was also oxidized to a sulfone or sulfoxide. The polarity of the sulfone or sulfoxide was greatly different from the polarity of the aromatic sulfur compound, and the sulfur oxide could be easily extracted.

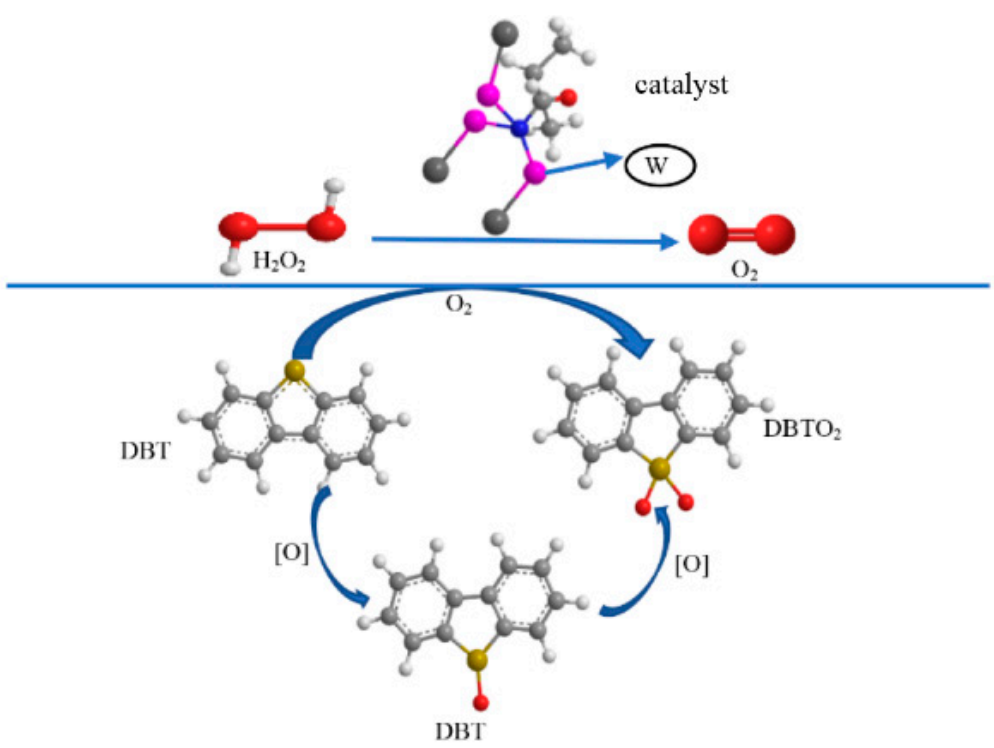

Figure 6. Oxidation mechanism diagram. 


\section{Conclusions}

In this study, HPW /PAM-10000 was successfully synthesized and characterized. The catalyst was effective for oxidative desulfurization, and the optimal process conditions were optimized. The detailed conclusions were as follows.

1. The FTIR figure showed that HPW/PAM was successfully synthesized because the characteristic peaks (-OH, -NH-) occurred. SEM results showed that when the load amount was larger, the amount of heteropoly acid would be larger, and the distributed curtain state was much more uniform.

2. The catalyst desulfurization optimal process condition was as follows. The temperature was $60{ }^{\circ} \mathrm{C}$, catalyst amount was $0.2 \mathrm{~g}$, the oxygen to sulfur ratio was 16 , and the reaction time is $100 \mathrm{~min}$.

3. The catalyst had high desulfurization efficiency after recycle use 10 times, so the catalyst stability was suitable for the industrial application.

4. The mechanism for the oxidative desulfurization process was put forward. Hydrogen peroxide could produce water and oxygen. Then, after a series of reactions, the desulfurization process occurred.

5. The HPW/PAM-10000 was environmentally friendly and economically feasible.

Author Contributions: Conceptualization, Z.Z. and Q.W.; Formal analysis, Z.Z.; Funding acquisition, Q.W.; Methodology, S.Z.; Writing-Z.Z. All authors have read and agreed to the published version of the manuscript.

Funding: This research was funded by the National Social Science Fund of China, grant number was 20CGL046.

Institutional Review Board Statement: Not applicable.

Informed Consent Statement: Not applicable.

Data Availability Statement: Not applicable.

Conflicts of Interest: The authors declare no conflict of interest.

\section{References}

1. Van Haandel, L.; Bremmer, G.M.; Hensen, E.J.M.; Weber, T. Influence of sulfiding agent and pressure on structure and performance of $\mathrm{CoMo} / \mathrm{Al}_{2} \mathrm{O}_{3}$ hydrodesulfurization catalysts. J. Catal. 2016, 342, 27-39. [CrossRef]

2. Yang, L.; Li, X.; Wang, A.J.; Prins, R.; Chen, Y.Y.; Duan, X.P. Hydrodesulfurization of dibenzothiophene, 4,6-dimethyldibenzothiophene, and their hydrogenated intermediates over bulk tungsten phosphide. J. Catal. 2015, 330, 330-343. [CrossRef]

3. Jiang, B.; Yang, H.W.; Zhang, L.H.; Zhang, R.Y.; Sun, Y.L.; Huang, Y. Efficient oxidative desulfurization of diesel fuel using amide-based ionic liquids. Chem. Eng. J. 2016, 283, 89-96. [CrossRef]

4. Ishihara, A.; Wang, D.H.; Dumeignil, F.; Amano, H.; Qian, E.W.H.; Kabe, T. Oxidative desulfurization and denitrogenation of a light gas oil using an oxidation/adsorption continuous flow process. Appl. Catal. A-Gen. 2005, 279, 279-287. [CrossRef]

5. Gao, S.R.; Li, J.Y.; Chen, X.C.; Abdeltawab, A.A.; Yakout, S.M.; Yu, G.R. A combination desulfurization method for diesel fuel: Oxidation by ionic liquid with extraction by solvent. Fuel 2018, 224, 545-551. [CrossRef]

6. Gao, S.R.; Chen, X.C.; Xi, X.T.; Abro, M.; Afzal, W.; Abro, R.; Yu, G.R. Coupled Oxidation-Extraction Desulfurization: A Novel Evaluation for Diesel Fuel. ACS Sustain. Chem. Eng. 2019, 7, 5660-5668. [CrossRef]

7. Cai, Y.J.; Song, H.Y.; An, Z.; Xiang, X.; Shu, X.; He, J. The confined space electron transfer in phosphotungstate intercalated ZnAl-LDHs enhances its photocatalytic performance for oxidation/extraction desulfurization of model oil in air. Green Chem. 2018, 20, 5509-5519. [CrossRef]

8. Xia, Y.T.; Li, Y.K.; Gu, Y.T.; Jin, T.; Yang, Q.; Hu, J.; Liu, H.L.; Wang, H.L. Adsorption desulfurization by hierarchical porous organic polymer of poly-methylbenzene with metal impregnation. Fuel 2016, 170, 100-106. [CrossRef]

9. Menzel, R.; Iruretagoyena, D.; Wang, Y.F.; Bawaked, S.M.; Mokhtar, M.; Al-Thabaiti, S.A.; Basahel, S.N.; Shaffer, M.S.P. Graphene oxide/mixed metal oxide hybrid materials for enhanced adsorption desulfurization of liquid hydrocarbon fuels. Fuel 2016, 181, 531-536. [CrossRef]

10. Xiong, J.; Yang, L.; Chao, Y.H.; Pang, J.Y.; Zhang, M.; Zhu, W.S.; Li, H.M. Boron Nitride Mesoporous Nanowires with Doped Oxygen Atoms for the Remarkable Adsorption Desulfurization Performance from Fuels. ACS Sustain. Chem. Eng. 2016, 4, 4457-4464. [CrossRef]

11. Xu, J.C.; Zhang, B.; Lu, Y.K.; Wang, L.G.; Tao, W.Y.; Teng, X.; Ning, W.S.; Zhang, Z.K. Adsorption desulfurization performance of $\mathrm{PdO} / \mathrm{SiO}_{2} @$ graphene oxide hybrid aerogel: Influence of graphene oxide. J. Hazard. Mater. 2022, 421, 126680. [CrossRef] [PubMed] 
12. Rizzo, C.; Misia, G.; Marullo, S.; Billeci, F.; D'Anna, F. Bio-based chitosan and cellulose ionic liquid gels: Polymeric soft materials for the desulfurization of fuel. Green Chem. 2022, 24, 1318-1334. [CrossRef]

13. Wang, J.; Yang, B.; Peng, X.L.; Ding, Y.C.; Yu, S.S.; Zhang, F.Q.; Zhang, L.F.; Wu, H.D.; Guo, J. Design and preparation of polyoxometalate-based catalyst $[\mathrm{MIMPs}]_{3} \mathrm{PMo}_{6} \mathrm{~W}_{6} \mathrm{O}_{40}$ and its application in deep oxidative desulfurization with excellent recycle performance and low molar O/S ratio. Chem. Eng. J. 2022, 429, 132446. [CrossRef]

14. Su, T.; Chi, M.Y.; Chang, H.Y.; Jin, Y.; Liao, W.P.; Ren, W.Z.; Zhao, D.Y.; Len, C.; Lu, H.Y. Enhanced oxidative desulfurization of fuel in ionic liquid by $\mathrm{TiO}_{2}$ quantum dots catalysts modified with Anderson-type polyoxometalate. Colloid Surf. A-Physicochem. Eng. Asp. 2022, 632, 127821. [CrossRef]

15. Wang, F.; Liu, Y.F.; Lv, Y.; Ren, J.; Wang, R.X.; Jiao, W.Z. Oxidative desulfurization of liquid fuels catalyzed by $\mathrm{W}_{2} \mathrm{C} @ \mathrm{C}$ derived from metallophthalocyanine/phosphotungstic acid composites. Sep. Purif. Technol. 2022, 281, 119953. [CrossRef]

16. Zhong, J.T.; Qi, Z.Y.; Liu, Y.Y.; Zhu, Y.X.; Chen, J.; Ye, C.S.; Qiu, T. Preparation of Zr-Based Phosphotungstic Acid Catalyst, ZrPTAX-BTC, and Its Application in Ultradeep and Fast Oxidative Desulfurization of Fuels. Ind. Eng. Chem. Res. 2022, 61, 977-986. [CrossRef]

17. Miao, G.; Huang, D.S.; Ren, X.L.; Li, X.; Li, Z.; Xiao, J. Visible-light induced photocatalytic oxidative desulfurization using $\mathrm{BiVO}_{4} / \mathrm{C}_{3} \mathrm{~N}_{4} @ \mathrm{SiO}_{2}$ with air/cumene hydroperoxide under ambient conditions. Appl. Catal. B-Environ. 2016, 192, 72-79. [CrossRef]

18. Yi, H.H.; Yang, K.; Tang, X.L.; Liu, X.; Zhao, S.Z.; Gao, F.Y.; Huang, Y.H.; Yang, Z.Y.; Wang, J.G.; Shi, Y.R. Effects of preparation conditions on the performance of simultaneous desulfurization and denitrification over $\mathrm{SiO}_{2}-\mathrm{MnOx}$ composites. J. Clean. Prod. 2018, 189, 627-634. [CrossRef]

19. Zhang, J.; Sun, S.; Bian, Y.H.; Li, W.K.; Liu, R.; Zhao, D.S. Adsorptive desulfurization of metal phthalocyanine functionalized poly-ionic liquids grafted to silica gel. Fuel 2018, 220, 513-520. [CrossRef]

20. Chen, Y.; Song, H.Y.; Lu, Y.Z.; Meng, H.; Li, C.X.; Lei, Z.G.; Chen, B.H. Unified Catalytic Oxidation-Adsorption Desulfurization Process Using Cumene Hydroperoxide as Oxidant and Vanadate Based Polyionic Liquid as Catalyst and Sorbent. Ind. Eng. Chem. Res. 2016, 55, 10394-10403. [CrossRef]

21. Chaukura, N.; Mamba, B.B.; Mishra, S.B. Porous materials for the sorption of emerging organic pollutants from aqueous systems: The case for conjugated microporous polymers. J. Water Process Eng. 2017, 16, 223-232. [CrossRef]

22. Zaidi, Z.; Sorokhaibam, L.G. Sequential Approach to Liquid Fuel Desulfurization through Rhodococcus erythropolis Assisted Molybdenum Modified Euryale ferox Biomass. Energy Fuels 2022, 36, 1615-1625. [CrossRef]

23. Li, B.; Yun, Y.B.; Liu, G.C.; Li, C.L.; Li, X.Y.; Hilal, M.; Yang, W.; Wang, M.X. Direct contact membrane distillation with softening Pre-treatment for effective reclaiming flue gas desulfurization wastewater. Sep. Purif. Technol. 2021, 277, 119637. [CrossRef]

24. Yen, H.Y.; Yang, M.H. Modified solution-diffusion model analysis of the flue gas desulfurization effluents in a polyamide membrane. Polym. Test. 2003, 22, 109-113. [CrossRef]

25. Yu, S.N.; Jiang, Z.Y.; Yang, S.; Ding, H.; Zhou, B.F.; Gu, K.; Yang, D.; Pan, F.S.; Wang, B.Y.; Wang, S.; et al. Highly swelling resistant membranes for model gasoline desulfurization. J. Membr. Sci. 2016, 514, 440-449. [CrossRef]

26. Wang, D.H.; Qian, E.W.H.; Amano, H.; Okata, K.; Ishihara, A.; Kabe, T. Oxidative desulfurization of fuel oil-Part I. Oxidation of dibenzothiophenes using tert-butyl hydroperoxide. Appl. Catal. A-Gen. 2003, 253, 91-99. [CrossRef]

27. Liu, Y.B.; Chu, J.F.; Lian, L.F.; Chen, X.; An, S.; Hong, L.L.; Wang, D.Q.; Chen, W. Ultrafast Oxidative Desulfurization of Diesel Fuels by Mass Transfer Enhancement of Polyoxometalate Modified Alumina Catalysts. Energy Fuels 2021, 35, 2110-2120. [CrossRef]

28. Lu, C.Z.; Fu, H.; Li, H.P.; Zhao, H.; Cai, T.F. Oxidation-extraction desulfurization of model oil over Zr-ZSM-5/SBA-15 and kinetic study. Front. Chem. Sci. Eng. 2014, 8, 203-211. [CrossRef]

29. Masoomi, M.Y.; Bagheri, M.; Morsali, A. Application of Two Cobalt-Based Metal-Organic Frameworks as Oxidative Desulfurization Catalysts. Inorg. Chem. 2015, 54, 11269-11275. [CrossRef]

30. Abazari, R.; Sanati, S.; Morsali, A.; Slawin, A.; Carpenter-Warren, C.L. Dual-Purpose 3D Pillared Metal-Organic Framework with Excellent Properties for Catalysis of Oxidative Desulfurization and Energy Storage in Asymmetric Supercapacitor. ACS Appl. Mater. Interfaces 2019, 11, 14759-14773. [CrossRef]

31. Majid, M.F.; Zaid, H.F.M.; Kait, C.F.; Jumbri, K.; Lim, J.W.; Masri, A.N.; Ghani, S.M.M.; Yamagishi, H.; Yamamoto, Y.; Yuliarto, B. Liquid Polymer Eutectic Mixture for Integrated Extractive-Oxidative Desulfurization of Fuel Oil: An Optimization Study via Response Surface Methodology. Processes 2020, 8, 848. [CrossRef]

32. Kulikov, L.A.; Akopyan, A.V.; Polikarpova, P.D.; Zolotukhina, A.V.; Maximov, A.L.; Anisimov, A.V.; Karakhanov, E.A. Catalysts Based on Porous Polyaromatic Frameworks for Deep Oxidative Desulfurization of Model Fuel in Biphasic Conditions. Ind. Eng. Chem. Res. 2019, 58, 20562-20572. [CrossRef]

33. Wang, C.; Li, A.-R.; Ma, Y.-L. Phosphomolybdic acid niched in the metal-organic framework UiO-66 with defects: An efficient and stable catalyst for oxidative desulfurization. Fuel Process. Technol. 2021, 212, 106629. [CrossRef]

34. Li, A.; Song, H.; Meng, H.; Lu, Y.; Li, C. Poly(ionic liquid)s based nano core-shell catalyst $\mathrm{SiO}_{2} @$ V-PIL for efficient oxidative desulfurization of diesel. Appl. Catal. A Gen. 2021, 616, 118096. [CrossRef]

35. Doustkhah, E.; Mohtasham, H.; Hasani, M.; Ide, Y.; Rostamnia, S.; Tsunoji, N.; Assadi, M.H.N. Merging periodic mesoporous organosilica (PMO) with mesoporous aluminosilica (Al/Si-PMO): A catalyst for green oxidation. Mol. Catal. 2020, $482,110676$. [CrossRef] 
36. Wei, S.N.; He, H.J.; Cheng, Y.; Yang, C.P.; Zeng, G.M.; Qiu, L. Performances, kinetics and mechanisms of catalytic oxidative desulfurization from oils. RSC Adv. 2016, 6, 103253-103269. [CrossRef]

37. Li, X.Z.; Zhu, W.; Lu, X.W.; Zuo, S.X.; Yao, C.; Ni, C.Y. Integrated nanostructures of $\mathrm{CeO}_{2} /$ attapulgite/g- $\mathrm{C}_{3} \mathrm{~N}_{4}$ as efficient catalyst for photocatalytic desulfurization: Mechanism, kinetics and influencing factors. Chem. Eng. J. 2017, 326, 87-98. [CrossRef]

38. Yu, F.L.; Wang, Q.Y.; Yuan, B.; Xie, C.X.; Yu, S.T. Alkylation desulfurization of FCC gasoline over organic-inorganic heteropoly acid catalyst. Chem. Eng. J. 2017, 309, 298-304. [CrossRef]

39. Li, S.W.; Gao, R.M.; Zhao, J.S. Deep Oxidative Desulfurization of Fuel Catalyzed by Modified Heteropolyacid: The Comparison Performance of Three Kinds of Ionic Liquids. ACS Sustain. Chem. Eng. 2018, 6, 15858-15866. [CrossRef]

40. Jiang, W.; Zhu, W.S.; Chang, Y.H.; Chao, Y.H.; Yin, S.; Liu, H.; Zhu, F.X.; Li, H.M. Ionic liquid extraction and catalytic oxidative desulfurization of fuels using dialkylpiperidinium tetrachloroferrates catalysts. Chem. Eng. J. 2014, 250, 48-54. [CrossRef]

41. Zhao, W.T.; Zheng, X.H.; Liang, S.J.; Zheng, X.X.; Shen, L.J.; Liu, F.J.; Cao, Y.N.; Wei, Z.; Jiang, L.L. Fe-doped-Al ${ }_{2} \mathrm{O}_{3}$ porous hollow microspheres for enhanced oxidative desulfurization: Facile fabrication and reaction mechanism. Green Chem. 2018, 20, 4645-4654. [CrossRef] 